\title{
Singular Thoughts and De Re Attitude Reports *
}

\author{
James Openshaw \\ [Penultimate draft. Forthcoming in Mind \& Language.]
}

It is widely supposed that if there is to be a plausible connection between the truth of a de re attitude report about a subject and that subject's possession of a singular thought, then 'acquaintance'-style requirements on singular thought must be rejected. I show that this belief rests on poorly motivated claims about how we talk about the attitudes. I offer a framework for propositional attitude reports which provides both attractive solutions to recalcitrant puzzle cases and the key to preserving acquaintance constraints. The upshot is that there is an independently motivated response to the principal argument against acquaintance.

\section{Introduction}

There is a distinctive way of representing objects which orthodoxy calls entertaining a singular thought. When I look at Leonard the cat and make a judgment I would express by saying 'He is tired', my thought is in an intuitive sense about Leonard. This kind of aboutness has long seemed importantly different to that involved in a thought I might entertain about the first cat to have been born at sea (whichever cat that was). In the second case, the best I am in a position to do is to form a thought which is satisfied by some cat, and which would be perfectly thinkable had that cat never existed. At least in their paradigm cases, singular thoughts are thinkable on the basis of some epistemically rewarding relation to the object in question, and are not thinkable where

\footnotetext{
${ }^{*}$ For questions and discussion I am grateful to audiences at an Oxford D.Phil seminar and a 2017 meeting of the APA Central Division in Kansas City. Special thanks to Bill Child, Martin Davies, Paul Elbourne, Rachel Goodman, John Hawthorne, Robin Jeshion, Michael Price, Tim Williamson, Andy Yu, and an anonymous referee for their generous comments. Thanks also to the AHRC and the Royal Institute of Philosophy for financial support during this period of research.
} 
there is no purported object. While it is controversial how singular thoughts are to be characterized exactly, it is not controversial that there are singular thoughts. Writers from Russell (1910/11) and Evans (1982) to Burge (2007) have suggested that singular thoughts are prerequisites for the possibility of empirical knowledge and perhaps for the possibility of thought per se. Strawson's (1959) massive reduplication thought-experiment suggests that, without singular thoughts, were it to turn out that the actual world consists of qualitative duplicate regions, we would be incapable of entertaining thoughts whose truth-values are determined by our region alone.

On the received view, one entertains a singular thought if and only if one bears a propositional attitude (e.g. belief or desire) to a certain sort of content_namely, a singular content. Having such a thought about an object is incompatible with its nonexistence. Singular thoughts, we might say, are object-dependent for contentfulness: they are contentful in virtue of there being some object they represent. ${ }^{1}$ Since their very contentfulness hinges on their being about a particular object, it is standard to think of the contents expressed by singular thoughts as being object-dependent. According to the Russellian picture assumed here, singular content is sodistinguished by virtue of being partly constituted by the represented objects themselves. (While this assumption will be congenial in what follows, it will not bias the discussion or seriously restrict the proposal's application to those who share it. Everything said will be translatable into a neo-Fregean framework, according to which singular contents contain object-dependent senses. ${ }^{2}$ )

\footnotetext{
1 The received view is not uncontroversial. Some deny that bearing an attitude to a singular content suffices for entertaining a singular thought (e.g. Récanati, 2012); some deny that singular thoughts have much to do with distinctions at the level of content (e.g. Stalnaker, 1984); and some support the availability of singular thoughts about non-existent objects (e.g. Crane, 2013). Still, many of the alternative characterizations will also ultimately be targets of the argument addressed in what follows.

2 McDowell (2009) suggests that the sort of treatment assumed here, which captures phenomena of cognitive significance by keeping track of the representational vehicle by means of which a Russellian content is expressed, is 'a mere notational variant' of the neo-Fregean's (2009, p. 178). Other prominent neo-Fregeans have recently opted to talk of mental files: 'representational vehicle[s] that [play] the role of mode of presentation' (Récanati, 2012, p. 244). Récanati is explicit that these are entities of the sort to which Russellians have traditionally appealed (p. 13, n. 6).
} 
It has long been tempting to think that part of what explains the distinctive epistemological and semantic features of singular thought is that the availability of such thoughts is subject to a distinctive constraint. Adopting Russell's (1910/11) nomenclature, we can call these acquaintance constraints: a subject must be acquainted with an object in order to entertain a singular thought about it. While there is a lively debate about what it is, exactly, to be acquainted with an object (in the term's post-Russellian usage), it has been common to suppose that singular thoughts are subject to a substantive constraint of this sort. As Davies (1981) summarized the extent of the consensus, which has grown little in the interim:

The negative partial answer is that if a person is totally causally isolated from the object then he can have no singular beliefs concerning it. The positive partial answer is that if a person has had frequent perceptual (particularly visual) contact with the object and is able reliably $[\ldots]$ to recognize the object $[\ldots]$ then he can have singular beliefs concerning it (1981: 97).

I will use 'acquaintance' liberally throughout as an umbrella term for any distinctive requirement bearing family resemblances to the paradigm constraints in the literature. The reader is invited to substitute appearances of 'acquaintance' with her favourite general constraint—whether causal (e.g. Kaplan, 1968), epistemic (e.g. Evans, 1982), or cognitivist (e.g. Jeshion, 2010).

Unfortunately, an influential argument stands in the way of the claim that there is any sort of acquaintance constraint on singular thought. Acquaintance constraints, it is alleged, are incompatible with our best account(s) of the connection between singular thoughts and the way in which we ascribe thoughts in ordinary language — specifically through the use of sentences of the following form:

Alice believes that Benjamin is kind. 
By analogy with the level of singular thought, there exists a class of singular terms: terms whose presence in a sentence suffices for the expression of singular content. Paradigm examples of these terms include proper names such as 'Benjamin' and deictic pronouns such as 'I' and 'that'. We can call propositional attitude reports like 'Alice believes that Benjamin is kind', in which a singular term features in the 'that-' clause, de re. ('De re' is to therefore be read as a property of reporting constructions, not of the attitudes reported.) According to a tempting line of thought, true de re attitude reports provide a window onto the presence of singular thoughts. If the predicate 'believes that Benjamin is kind' is true of Alice, or if 'believes that $x$ is kind' is true of Alice on an assignment of Benjamin to ' $x$ ', it would appear that Alice believes a singular content about Benjamin, and, for that matter, that she must entertain a singular thought about him. ${ }^{3}$ We can summarise these claims about the connection between singular thoughts and de re attitude reports as follows. ${ }^{4}$

HARMONY: Any belief ascription whose 'that-' clause contains, at the level of logical form, a singular term referring to some thing, $o$, or an objectual variable bound from outside the scope of the belief operator and assigned $o$ as its value, requires for its truth that the subject believe a singular content about 0 .

SUFFICIENCY: Believing a singular content about some thing, $o$, is sufficient for entertaining a singular thought about 0 .

The next section sets out the classic argument against acquaintance, most recently-and to many convincingly_pressed by Hawthorne and Manley (2012; 2014). It will become clear that even those persuaded by Hawthorne and Manley's careful discussion should be interested in the response defended here. In $\$ 2$ I outline that response. I advance a powerful and

\footnotetext{
${ }^{3}$ I say that this line of thought is tempting, but it will be clear by the end of the paper that it requires sophistication. Readers who find it antecedently naïve or implausible are encouraged to continue.

4 Both principles are adapted from Hawthorne and Manley (2012, p. 38).
} 
independently attractive semantic framework for propositional attitude reports in $\$ 3$, and deploy that framework in $\int \ 4-5$ to secure the acquaintance-theorist's response. The upshot is that there is an independently motivated response to the dominant argument against acquaintance-theoretic ideology.

\section{The argument from attitude reports}

In their (2012), Hawthorne and Manley use HARMONY and SUFFICIENCY to highlight the raft of problem cases known to exist for anyone hoping to endorse the following thesis:

CONSTRAINT: For $S$ to entertain a singular thought about $o, S$ must be acquainted with $o$.

Call supporters of CONSTRAINT acquaintance theorists. Notice that HARMONY and SUFFICIENCY are not claims of which acquaintance theorists are likely to be especially wary. Part of the prima facie motivation for thinking that there is a distinctive kind of representation in the vicinity falls out of a cursory look at some attitude reporting practices, and part of the prima facie motivation for positing an acquaintance constraint is to explain these practices. The rough idea is this. Suppose Ralph believes, like you and I, that there are spies, and so that there is at least one spy. (The example is due to Quine (1956).)

(1) Ralph believes that there is at least one spy.

$\left(1^{*}\right) \quad$ Ralph believes that $\exists x(\operatorname{Spy}(x))$

But Ralph has never encountered a spy. His belief is of a mundane, general sort, and would not, unlike (2) —informally regimented as the de re ascription (2*) — be of interest to MI5.

(2) There is some thing such that Ralph believes it to be a spy. 
The acquaintance theorist can use HARMONY and SUFFICIENCY in conjunction with CONSTRAINT to explain why (2) is false while (1) is true. (2) is false because Ralph is not acquainted with any spy.

Now for the problem cases. There are instances of true, de re attitude ascriptions where it is not clear that the subject bears any acquaintance-like relation to the res. And when we look at a sufficiently diverse range of such cases, it becomes clear, given the heterogeneity exhibited, that any constraint that might be said to hold is going to be highly disjunctive, epistemically indistinctive, and causally vacuous. ${ }^{5}$ And in that case our three principles are incompatible. Rather than go through such a series of cases here, I present one representative example where it is both unclear what acquaintance constraint could be said to obtain and plausible that the relevant de re attitude report is neither false nor deviant. ${ }^{6}$

Out of her profound admiration for the spies of MI6, Her Majesty the Queen has decided that each year she will award a Medal of Heroism. Since the files on spies are highly classified, however, she is required to hire an assistant, $\mathrm{M}$, to determine a recipient. She suggests that $\mathrm{M}$ award it to the top-performing spy in one of the six continents MI6's spies are posted in. The next day, $M$ assigns continents to the numbers 1-6 and rolls a fair die. Since it lands on 4, she concludes that the top-performing spy posted in Asia is to receive the honour. M consults the classified records and identifies the agent, who is named 'Bond'. Later, $\mathrm{M}$ informs the Queen only that a unique spy has been selected. In her speech congratulating Bond at the clandestine ceremony (from which the Queen is absent), M truly reports:

(3) The Queen believes that Bond is a hero.

\footnotetext{
${ }^{5}$ Hawthorne and Manley (2012) provide a thorough evaluation of the data.

${ }^{6}$ I owe the shape of this example to Goodman's $(2013 ; 2017)$ of the childless Gerard seeking an heir.
} 
Given HARMONY, the Queen believes a singular content, and so by SUFFICIENCY has a singular thought. But despite CONSTRAINT she is in no obvious way acquainted with Bond.

In light of cases of this sort, the consensus is that our three principles are incompatible: 'If one accepts HARMONY [and SUFFICIENCY], one has to give up acquaintance as a constraint on singular thought' (Récanati, 2010, pp. 167-8). If that is right, acquaintance-theoretic ideology is indeed 'a dispensable relic of a bygone era' (Hawthorne and Manley, 2012, p. 25). Now this would be a profound conclusion. As Jeshion (2014) urges, the attempt to carve some line between canonical cases of singular thought and cases like the above precludes the identification of any explanatorily valuable acquaintance constraint, undermining the very distinction between singular and descriptive intentionality:

...however we explain [...] these sets of cases, what is truly left of the distinctionand, more important, the value of the distinction-between singular and descriptive thought? In my view, there remains no contentful, philosophically fruitful distinction [...] (2014, pp. 84-5).

Acquaintance-lovers will want to take a hard look at HARMONY and SUFFICIENCY. SUFFICIENCY, as Hawthorne and Manley put it, is 'simply a consequence of a common characterisation of singular thought' (2012, p. 38). As for HARMONY, some philosophers (Schiffer, 1978, p. 181; Récanati, 1993, p. 362) have argued that while Russellian singular contents are expressed by the 'that-' clauses of attitude reports, they are just not the kind of thing which could be the 'complete content' of a thought, for they will fail to reflect facts about cognitive significance. To believe a singular content is, rather, to believe it under some mode of presentation or 'guise'. These philosophers will take issue with the letter of HARMONY. However, they will not thereby find anything untoward in its spirit, since they can easily allow that de re belief reports require for their truth that the subject believe a 'quasi-singular' content (Schiffer, 1978, p. 182): a singular content

\footnotetext{
${ }^{7}$ Compare Evans' (1982, p. 199) remark on the implications of tying the presence of a singular thought to the 'rag-bag category' of cases in which we are inclined to use certain psychological idioms.
} 
along with some (perhaps contextually-determined) mode of presentation of the relevant object. ${ }^{8}$ The intent of HARMONY, then, is not to deny that modes of presentation or guises can be truthconditionally relevant. It is just to insist that if the content of a 'that-' clause is singular with respect to 0 , the content believed by the subject must, whatever else it may come with, be likewise singular (or quasi-singular) with respect to $o$.

While HARMONY is certainly not sacred, it is supported by the following intuitive picture of how attitude reports work. Expressions embedded in 'that-' clauses have the same semantic values as when they are unembedded. The semantic value of a 'that-' clause is a content. And belief reports express relations between subjects and contents. So long as 'believes' expresses the attitude of belief, then, if a 'that-' clause is de re it will require for its truth that the subject believe a singular (at least, quasi-singular) content. A treatment capable of doing justice to the unquestionable subtlety of our ascription practices while nonetheless conforming to this intuitive picture is, at least, off to a good start. And if something like this treatment can be reconciled with CONSTRAINT, as I shall illustrate, it will have a lot going for it. Still, independently motivated rejections of HARMONY remain worthy of investigation. One might suppose, for example, that reports like (3) show that de re attitude reports do not require that the guise or mode of presentation under which the subject thinks of the res be a singular mode of presentation. One might then reject SUFFICIENCY, adding that believing a singular content under a descriptive guise does not suffice for entertaining a singular thought. The notion of singular thought must then be characterised independently of bearing an attitude to a singular content. Alternatively, one might reject HARMONY, instead supposing that singular contents cannot be believed under descriptive guises. What those interested in the latter option must provide is a compositional semantics which shows how, despite the mismatch, a belief report whose 'that-' clause expresses a singular content can be true in virtue of the subject believing a descriptive content. I leave it to those who

\footnotetext{
8 As Récanati (1993) emphasises, 'wherever a quasi-singular thought is expressed, a singular proposition [...] is also expressed' (pp. 375-6). In this way, HARMONY appears to be compatible with rejecting what Bach (1997) calls the 'specification' assumption.
} 
would prefer to reject HARMONY to offer a compelling, independently attractive defence of that rival strategy.

Though there is perhaps something to be said for the picture of attitude reports enshrined in the conjunction of HARMONY and SUFFICIENCY, it, too, is by no means sacred, and we should feel no regret for departing from it if doing so is required to do justice to the subtlety of our attitude-reporting practices. Indeed, a member of our inconsistent triad must go, or at least undergo qualification (given the argument from attitude reports), and I shall be arguing that it is not CONSTRAINT...

There is a range of alternative strategies one might deploy in response to the argument from attitude reports, each with venerable endorsements: rejecting HARMONY (Bach, 2014, p. 457); espousing an error-theory about ordinary language attitude ascriptions (Kaplan, 1989, p. 555, n. 71); construing what counts as acquaintance as context-dependent (Chalmers, 2011); or claiming that acquaintance is not a de facto constraint but a normative, de jure constraint which may be violated in practice (Récanati, 2010). The response I recommend emerges from an independently attractive framework which offers solutions not only to the acquaintance-theoretic puzzles represented by (3) but to a wealth of recalcitrant attitude-reporting data. This is a virtue which few of the above strategies have manifested. And while this strategy has its own small but venerable tradition (see below), it has yet to be explicitly developed.

In fact, Hawthorne and Manley and their followers should avail themselves of the antidote recommended here. Hawthorne and Manley call their view that singular thought is not 'tied to a special relation of causal or epistemic acquaintance' (2012: 3) —indeed is 'not subject to any interesting acquaintance constraint' (2012: 243)—liberalism. But there are two interesting and independent views in the vicinity of this negative thesis.

STRONG Liberalism: For $S$ to entertain a singular thought about $o, S$ need do nothing more than be in a position to entertain a paradigm descriptive thought about $0 .{ }^{9}$

\footnotetext{
9 Strong liberalism, or views resembling it, have sometimes gone by 'latitudinarianism' or '(the principle of) unrestricted exportation' (see Borg (2004), Harman (1977), Quine (1977), and Sosa (1970)). I qualify this
} 
WEAK LIBERALISM: For $S$ to entertain a singular thought about $o, S$ need not be acquainted with $o$, but $S$ must do something more than merely be in a position to entertain a paradigm descriptive thought about 0 .

Whether one counts as an acquaintance-theorist or a weak liberal will depend on the operative notion of acquaintance. On its Russellian (1910/11) interpretation, acquaintance-theorists will be scarce. But if 'acquaintance' is viewed as a term exhausted by its role in characterizing whatever constraints on singular thought there are, weak liberalism will cease to be an interesting category. I will not be taking any stances here, since my aim is only to show that even those with heavy duty conceptions of acquaintance have available an attractive and non-ad hoc response to the argument from attitude reports. ${ }^{10}$

Strong liberals deny that there are any distinctive and general requirements on singular thought. If this is correct, the very distinction between singular and descriptive thoughtbetween my thought about Leonard the cat and my thought about the first cat to have been born at sea-comes under strain. The important point is that the denial of CONSTRAINT is compatible with either of these views. This is important because the argument from attitude reports to which Hawthorne and Manley (2012) appeal, if not reined in, leads to the stronger conclusion, which they appear inclined to reject.

There are instances of true, de re attitude ascriptions where the subject is by all except the strong liberal's criteria incapable of entertaining a singular thought about the object in question. ${ }^{11}$ Suppose Phyllis comes across a blog post in which the author, Alice, who has little familiarity with philosophy, and not the slightest with any of its practitioners, claims that all philosophers

attribution since the denial of acquaintance constraints on de re attitude reports has sometimes failed to be distinguished from, or has been mistaken for, the denial of such constraints on singular thought.

${ }^{10}$ One valuable way of drawing the distinction would be to relativise it to independently characterised thoughttypes. It may be that one's view on the requirements for perceptual-demonstrative singular thought involves a sufficiently acquaintance-like relation to merit that label, but that in the case of communication-based singular thoughts or thoughts about tomorrow, for example, one's views are less exacting.

11 The following example is adapted from Hawthorne and Manley (2012, p. 51). 
are engaged in a worthless enterprise. We can easily imagine a scenario in which Phyllis speaks truly when she reports

(4) Alice believes that I am engaged in a worthless enterprise.

Hawthorne and Manley are not uninterested in potential 'form-theoretic distinction[s]' between kinds of mental object-representation (2014, p. 507), and in 'referential vehicles of thought' (2012, p. 246), 'tags, files, or terms of Mentalese' (2012, p. 247). And this is a good thing. For it seems scarcely plausible that there should be a notion with the epistemological and semantic import mentioned at the outset whose conditions for being realized are trivial or vacuous. Their worry, rather, is that 'muddled ideas about acquaintance' are liable to counteract whatever progress is made on 'the role of object representations in our cognitive economy' (2012, p. 248). So while Hawthorne and Manley's (2012) contribution to the debate concerning the requirements on entertaining a singular thought is a negative one, they are at least amenable to the view that something distinguishes episodes of singular thought from those of descriptive thought. Canvassing options for the weak liberal in response to cases like (4), Hawthorne and Manley suggest that perhaps whenever a thinker believes there to be a unique $F$ she either habitually does or easily can form a mental file or tag which is referential. But of course, Alice's description is indefinite. Alternatively, they suggest, perhaps there are situations where singular thought itself is easy to come by (2012, p. 51). In contexts where (4) comes out true, it is true in virtue of Alice possessing a singular thought. However, I take it that if singular thought itself turns out to be a heavily situation-dependent phenomenon, it will be of limited theoretical interest, and incapable of sustaining the epistemological and semantic roles with which it is associated. ${ }^{12}$ The strategy I recommend here, then, is likely to be refreshing, not only for the

12 On the claim that strong liberalism collapses into a kind of eliminativism about singular thought, see Goodman (2017) and Récanati (2010, p. 168). Hawthorne and Manley seem willing to concede this result (2012, p. 52, n. 32). 
noble acquaintance-theorist, but for anyone persuaded by Hawthorne and Manley's (2012) who has come to see strong liberalism for the radical position that it is.

In this paper, I clarify and develop a view of the connection between singular thoughts and de re attitude reports which has been suggested by Evans (1982), Peacocke (1983), Chalmers (2011), and most recently Goodman (2013; 2017). I argue that in addition to being independently attractive, it allows us to maintain both CONSTRAINT and HARMONY while also, as a bonus, preserving the classic acquaintance-theoretic explanation of (2)'s falsity at the imagined context. While one of the upshots is that SUFFICIENCY must be rejected in its unqualified form, there is a robust sense in which it remains universally true, and its use in the acquaintance-theoretic explanation of (2)'s falsity can be retained. Insofar as sacrifices must be made concerning the SUFFICIENCY principle, then, these should come to seem independently plausible. What has made the liberal's argument compelling is an implicit, poorly-motivated semantics. And once we have a semantics which is sensitive to the subtleties of our ascription practices, a wealth of puzzlesand the principal argument against acquaintance-fall away. ${ }^{13}$

\section{Contextualism and singular thought}

Contextualists about attitude ascriptions think that constructions of the form ' $S$ S that $p$ ', where ' $\Phi$ ' is some propositional attitude verb (e.g. 'believes'), are context-sensitive. It is possible for two speakers to literally and sincerely assert ' $S \Phi$ s that $p$ ' and 'It is not the case that $S \Phi$ s that $p$ ', respectively, and for each to speak truly. Where this occurs, the contexts at which these sentences

13 Broadly similar semantics are discussed in Bach (1997; 2010), Chalmers (2011), Cumming (2013), Forbes (1987), Récanati (1993), and Richard (1990). In a separate vein, Evans (1982) insists that certain ordinary language attitude expressions have only a loose connection to the level of mental representation he calls understanding. This is echoed in Chalmers (2011, p. 612), Peacocke (1983, pp. 196-7), and especially Goodman (2013; 2017). However, it is sometimes unclear whether these authors mean to reject HARMONY (see Evans (1982, p. 129)). I clarify and extend the latter train of thought by advancing a semantics akin to the former group of authors. 
are used will differ in respect of some feature to which the construction ' $S \Phi$ s that $p$ ' is sensitive. The sort of contextualist I have in mind will deny that the speakers express the same semantic content in their respective uses of the sentence ' $S \Phi$ s that $\not$ ', for there are many belief-relations which can be expressed by the attitude verb 'believes'. Which belief-relation is expressed by a use of 'believes' at a context is partly determined by features of the (extra-linguistic) context, such as the purposes, expectations, and presuppositions of the speakers using these sentences. We might say that ordinary language propositional attitude verbs are indexical expressions. The moral, in any case, is that the role played by attitude-reporting sentences of the form ' $S \Phi$ s that $p$ ' in our linguistic practice is not well-served by the specification of some unique and complete semantic content as their compositional semantic value.

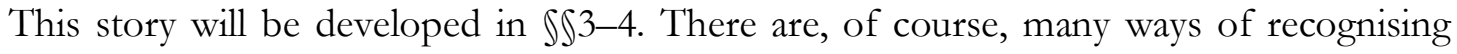
context-sensitivity in attitude-reporting sentences. Assuming the phenomenon is triggered by some syntactic constituent at logical form, it may be located in the attitude verb (e.g. Richard, 1990), in the complementiser 'that-' (e.g. Chalmers, 2011), in some covert indexical (e.g. Schiffer, 1978), or in the report's 'that-' clause: 'that $p$ ' (e.g. Récanati, 1993, p. 397). Alternatively, we might take the relevant contextually determined propositional constituent to be 'unarticulated' (Crimmins and Perry, 1989). Or we might take the semantic content of ' $S$ believes that $p$ ' on an occasion of use to be incomplete or underdetermined (Bach, 1994). ${ }^{14}$ My rationale for presupposing an indexical, 'verbalist' framework in this paper will become clear.

The upshot of the semantic framework advanced in $\int \mathbb{S} 3-4$ is that appearances of 'belief', 'believes', etc. in HARMONY and SUFFICIENCY are context-sensitive. What believing a singular content amounts to, and what it requires of a subject, is a context-dependent matter. However, expressions such as 'singular thought' are theoretical terms of art which do not contain contextsensitive elements at logical form. Whether a subject has a singular thought is not a contextdependent matter. On a conception of singular thought constitutively tied to a distinction at the

\footnotetext{
${ }^{14}$ Such views could be reconciled with the claim that the context-sensitivity of ' $S \Phi$ s that $p$ ' is always triggered by some elementary constituent at logical form, since we could assign 'incomplete' semantic values at that level.
} 
level of content, there will be some relation(s) the bearing of which by a subject to a content is not a context-dependent matter. And, as a corollary, whether a subject is acquainted with an entity will not be a context-dependent matter. Consequently, there is a nearby principle which the acquaintance-theorist must reject:

CONCORD: Any belief ascription whose 'that-' clause contains, at the level of logical form, a singular term referring to some thing, $o$, or an objectual variable bound from outside the scope of the belief operator and assigned $o$ as its value, requires for its truth that the subject entertain a singular thought about 0 .

Note that CONCORD is an abridged form of HARMONY and SUFFICIENCY, absent the contextsensitive appearances of 'believe' and 'believing'. CONCORD claims that at all contexts at which a true, de re belief ascription is made, the attributee entertains a singular thought. The key point is that HARMONY and SUFFICIENCY, as presented above, leave open the possibility that the appearances of 'believe' (in HARMONY) and 'believing' (in SUFFICIENCY) might express different belief-relations. CONCORD eliminates this possibility, closing the gap which permitted nonuniform interpretation.

While HARMONY remains true for every possible relation expressed by a use of 'believes' at a context, this is not true for SUFFICIENCY. Some contexts place undemanding requirements on what a thinker must do in order that she fall under the ordinary language predicate 'believes that $p^{\prime}$ and, where $p$ is a singular content, it is possible that those requirements are outstripped by the (context-invariant) requirements on entertaining a singular thought. In that case, SUFFICIENCY must be rejected. Some belief-relations one can bear to a singular content do not suffice for one's entertaining a singular thought. As we will see, those expressed by the uses of 'believes' in the contexts of (3) and (4) are of precisely this sort.

What is essential to this move is that the acquaintance theorist will adopt 'entertains' as a theoretical term of art, sensitive to the explanatory purposes of her theory of mind. In a variety of guises, philosophers have claimed that a thinker may fail to occupy a belief state, say, with the 
content that $p$, despite falling under the ordinary language predicate 'believes that $p$ ' at some context. ${ }^{15}$ It is this sort of move which the acquaintance-theorist will deploy at this point in her response to the argument from attitude reports.

[A subject] could be sensibly described as believing that $N N$ is $F[\ldots]$. But it seems to me that this sort of belief-ascription is very closely tied to [her] disposition to say that $\mathrm{NN}$ is $\mathrm{F}[\ldots]$. And this leaves the substantive question, whether [she] can entertain [singular] thoughts about the referent, in the sense which concerns us, untouched (Evans, 1982, p. 401).

...to say that someone believes a proposition is to give a fairly coarse-grained description of their psychological state, $[\ldots]$ compatible with numerous more finegrained descriptions of the $[\ldots]$ proposition that they endorse (Chalmers, 2011, p. 612). [...] 'endorse' is [...] a technical term (p. 604) [which] captures the underlying cognitive state of believers (p. 619).

Despite the nomenclature, entertaining or endorsing a proposition need not be an occurrent mental act (unless, of course, one's theory of mind is only interested in specifying contents for these purposes). Though I may be accused of terminological abuse, I follow the precedents of Evans (1982) and Goodman (2017) in adopting 'entertains' as a term of art, since I hesitate to introduce further terminology. In what follows, I attach ${ }^{\text {(+) }}$ to ordinary language attitude verbs when I mean to pick out this underlying level of psychological reality. What is not obvious, in sum, is that the relations expressed by ordinary language attitude verbs track our invariant entertains relation. While there may be little of philosophical interest to say about the requirements on falling under the ordinary language predicate 'believes that $p$ ' at a context, where $p$ is a singular content, there

\footnotetext{
15 Evans (1982) and Goodman (2013; 2017) appeal to the notion of 'entertaining', Peacocke (1983, pp. 196-7) to the 'Bel' relation, and Chalmers (2011) to 'endorsing'. Dorr (2011, pp. 940-1) similarly categorises Loar's (1988) notion of 'psychological content', Stalnaker's (1988) 'compatibility with a subject's beliefs', and Lewis' (1979) 'the objects of belief. See also Bach's (1997) claim that 'belief reports do not report beliefs' (p. 215).
} 
may be much of philosophical interest to say about the requirements on entertaining a singular thought—or, believing ${ }^{+}$that $p$.

This is not to say that ordinary language attitude verbs are of no serious semantic or theoretical interest. For example, even if it were insisted that 'believes' often fails to capture some philosophically significant level of content, it expresses (at a context) a relation which will interest us in marking relations of agreement and disagreement between conversational participants. ${ }^{16}$

The core of the strategy against the argument in $\$ 1$ is the rejection of SUFFICIENCY except at privileged, theoretical contexts. The rejection of SUFFICIENCY on its own is not a claim about the semantic structure of propositional attitude-reporting sentences. While those wedded to other accounts of propositional attitude reports may be attracted to rejecting SUFFICIENCY, my claim that SUFFICIENCY holds at certain privileged contexts (those, roughly, at which the speakers are engaged in the theory of mind) suggests that there are many belief-relations expressible by 'believes', some of which, when borne to a singular content, do suffice for the possession ${ }^{+}$of a singular thought. HARMONY will then come out true on any uniform interpretation of 'belief' and 'believe' if we suppose that the context-sensitivity of attitude reports consists in the contextdependence of the 'belief relation. $\int \mathbb{S 3 - 5}$ show that this sort of picture of the connection between de re reports and singular thoughts can be clarified and motivated in an independently appealing way. This development, however, involves sacrificing neutrality on the semantics of propositional attitude-reporting sentences (and, given a contextualist treatment, on the source and nature of their context-sensitivity). ${ }^{17}$ The rationale for maintaining SUFFICIENCY in qualified

\footnotetext{
${ }^{16}$ This point is made by Chalmers (2011, p. 619). 'Agreement' and 'disagreement' here are not to be thought of as attitude verbs but as relations to uses of sentences.

17 For reasons of space I am unable to provide an independent defence of verbalism over alternative treatments here, though responses to some natural objections against the view are provided in $\$ 4$. I do presuppose that error-theoretic and pragmatic accounts of the attitude-reporting phenomena below are incorrect. Attributing rampant error to speakers (Braun, 1988) is simply difficult to justify. It is possible to supplement this semantic outlook with a pragmatic story which explains differences in our untutored reactions (Salmon (1986); Soames (1987)). But there is a real worry that this story leads to too indirect a link between
} 
form is that detaching our account of singular thought entirely from the bearing of an attitude to a singular content threatens to leave us with little grip on the phenomenon (recall the introduction to singular thought given above). The qualification of SUFFICIENCY lets us characterise singular thought via the characterisation of belief ${ }^{+}$and the specification of those contexts at which 'belief', so to speak, amounts to belief ${ }^{+}$: for to believe ${ }^{+}$a singular content about o- to entertain a singular thought about o-one must be acquainted with 0 .

While we must reject the unqualified SUFFICIENCY principle, it is possible to claim that the appearance of the term of art 'singular thought' in SUFFICIENCY has the effect that, whenever SUFFICIENCY is uttered, it is true. Contextualists about knowledge have sometimes suggested that mere mention of a skeptical scenario is sufficient for its being a relevant alternative, a scenario which must be excluded by the subject if she is to possess the relevant piece of knowledge. Lewis (1996) suggests that the mere production of a knowledge report can suffice for the relevance of unattended-to possibilities:

I say $S$ knows that $P$ iff $P$ holds in every possibility left uneliminated by $S$ 's evidence-Psst! —except for those possibilities we are properly ignoring [...]. Do I claim you can know that a possibility $W$ does not obtain just by ignoring it? [...] Well, [...] I do not claim it for any specified $P$ or $W$. [... knowledge just by presupposing and ignoring is knowledge; but it is an especially elusive sort of knowledge. [...] Simply mentioning any particular case of this knowledge [...] is a way to attend to the hitherto ignored possibility [...] and thereby create a context in which it is no longer true to ascribe the knowledge (Lewis, 1996, pp. 561-2).

If this is correct, it is possible to suggest that 'Knowing a proposition is sufficient for undermining Cartesian scepticism' will be true whenever uttered, despite the fact that it is not true with respect to every relation which can be expressed by a use of 'knows'. By analogy, it is

semantic content and facts about use, draining the former of potential explanatory utility (see Récanati (1993, pp. 335-45)). 
possible to claim that 'Believing a singular content is sufficient for entertaining a singular thought' will be true whenever uttered. In the first case, it is the standards for knowledge which are raised by the relevance of skeptical scenarios. In the latter, it is the standards for believing $a$ singular content which are raised by the use of a theoretical term of art. For all that is to be said here, then, there may well remain a robust sense in which SUFFICIENCY is universally true. Arguing for this in any detail, however, is beyond the scope of this paper. Moreover, whether this is so is not especially important for our purposes. What is important is that as we explore the framework's attractive treatments of recalcitrant puzzle cases, the sacrifices made concerning the SUFFICIENCY principle shall come to seem independently plausible, complementing rather than undermining the considerations which made SUFFICIENCY seem like a natural principle to endorse.

\section{Blueprint for a contextualist semantics}

This section presents one particularly attractive shape for the sort of contextualist semantics discussed in $\$ 2$ and begins to explore its puzzle-dissolving power. While its treatment of de re ascriptions is emphasised here, it will be clear that an account of de dicto ascriptions is also provided. In $\$ 4$ I return to illustrate how the proposal should be used by acquaintance theorists to respond to the liberal's argument. For ease of exposition, I assume that contents have a Russellian structure, constituted by particulars, properties, and quasi-syntactic elements (see Salmon, 1986, pp. 143-51). I also assume a basic representational theory of mind, according to which propositional attitudes are logically and compositionally structured representations. It is not a commitment of the account that representations are shareable, and in the literature this sort of position usually departs from the Fregean tradition in this way: mental content-vehicles 'are not shareable like theories or conceptions, but are agent-bound like headaches' (Crimmins, 
1995, p. 465). ${ }^{18}$ Still, some headaches, I want to say, are more (interpersonally) similar than others.

Thinkers entertain Russellian contents under guises. And often, when we talk about thinkers' attitudes, we care about the how. The guise under which the subject of a de re belief report represents the res matters to us. Other times, as 'direct reference' theorists are wont to point out, we only care about the what. When we do care about the how, it seems that context plays a role in determining the standards of 'fit' required between a singular term in the ascription's 'that-' clause and a content-vehicle in the mind of the subject. This has often been referred to as the 'opacity/transparency' distinction. But there is arguably a sliding scale here: 'a continuum along which an embedded expression can be explicit about the vehicle of an attributed belief' (Fodor, 1990, p. 169).

The first move in our semantics is to think of there being a kind of set-theoretic entity determined by attitude ${ }^{+}$states and 'that-' clauses such that each element of the Russellian content expressed is paired with its representational vehicle. A sentence $S$, expressing the content that $p$, determines what I will call a sticky proposition: a pairing of the sub-sentential components of $S$ with the components of $p$ they respectively express. We are to think of 'that-' clauses as determining a proposition-like entity which is 'sticky': picking up the linguistic material by means of which its content is expressed. ${ }^{19}$ To see this in action, suppose $\mathrm{Ba}$ the Babylonian is looking at the night sky. His friend Ia says, 'Ba believes that Hesperus is bright'. We have two relevant sticky propositions, one (of many) determined by Ba's belief ${ }^{+}$state, one determined by Ia's use of 'that Hesperus is bright'. The Russellian component, which I will henceforth call the 'R-proposition', is preserved across each of the two sticky propositions. That is, we have the planet Venus and

\footnotetext{
18 Proponents of 'this sort of position' include Crimmins (1992; 1995), Crimmins and Perry (1989), Cumming (2013), Fodor (1990), Millikan (2000), Récanati (2012), Richard (1990), and Salmon (1986).

${ }^{19}$ I use 'determines' in connection with sticky propositions, reserving 'expresses' for semantic content proper. Sticky propositions are simply set-theoretic entities to which we as theorists may appeal in stating the truthconditions of attitude reports. This framework is closest to Richard's (1990; 2013), but the quasi-singular propositions of Schiffer (1978) et al. are also similar. Nonetheless, these writers do claim that 'RAMs' and quasi-singular propositions, respectively, are proper objects of belief (see, for example, Richard, 2013, p. 101).
} 
the property brightness. What differs are the representational vehicles. Where Ia uses a proper name to refer to Venus (o) and a predicate to refer to the property of brightness, Ba uses two cognitive vehicles, $R_{B a}^{1}$ and $R_{B a}^{2}$.

$$
\begin{aligned}
& \text { Ba: } \quad<<0, \mathrm{R}^{1}{ }_{\mathrm{Ba}}>,<\text { brightness, } \mathrm{R}^{2}{ }_{\mathrm{Ba}}>> \\
& \text { Ia: } \quad<<0, \text { 'Hesperus' }>,<\text { brightness, 'is bright' }>>
\end{aligned}
$$

What, then, makes Ia's belief ascription true? Is it just that she gets the R-proposition right? This looks much too weak. Would the report 'Ba believes that Venus is bright' be true? If Ia comes to learn that Hesperus is Phosphorus, would her ascription 'Ba believes that Phosphorus is bright (this evening)' be true? There are certain transparent readings of these ascriptions on which they get to express truths, but at most contexts 'Ba believes that Phosphorus is bright (this evening)' will ring false. How can we account for this diversity of intuitive truth-value assignments?

We can define a context-dependent relation between the sticky propositions determined by attitude ${ }^{+}$states and 'that-' clauses. Call it correlation. What correlation amounts to-whether or not two sticky propositions correlate or 'match' - will vary across contexts. In particular, belief reports express different belief-relations at different contexts. And which belief-relation is expressed on an occasion of use turns on the interpretation of a covert indexical, for which ordinary language attitude verbs contain an argument place, determined by the context's set of correlations between all sticky propositions. ${ }^{20}$ The generalised truth-conditions for attitude reports, in the ordinary case, will run: ' $\mathrm{NN}$ believes that $S$ ' is true at a context of use $c$ iff $\mathrm{NN}$ has a belief ${ }^{+}$in the Russellian content expressed by 'that $S$ ' (at c) and the sticky proposition

\footnotetext{
${ }^{20}$ These relations will be reflexive, symmetric, and transitive. In other words, a context of use will provide a partition on the space of sticky propositions. The transitivity condition is arguably required to accommodate inferences of the following sort: ' $A$ believes what $B$ believes'; ' $B$ believes what $C$ believes'; 'Therefore, $A$ believes what $C$ believes' (where no shift in context occurs). An account which, like Forbes' (1987), requires a context-dependent degree of similarity to obtain between 'sticky proposition'-like entities will have difficulties preserving the transitivity needed to underpin such inferences. Richard's (2013) notion of translation may also face these difficulties.
} 
determined by 'that $S$ ' correlates with the sticky proposition determined by NN's belief ${ }^{+}$in that content, where the standards for correlation are those operative at $c .^{21}$

This will all become clearer once we get to looking at some puzzle cases. Before that, however, allow me to briefly clarify the role of sticky propositions. Sticky propositions are a settheoretic resource appealed to when stating the truth-conditions of attitude-reporting sentences. They are not the objects of attitudes or the semantic values of sentences (certainly not if one takes there to be just one sort of entity which plays either of these roles). 'That-' clauses embed under quantificational and intensional operators in the usual way. We need not make sense of sticky propositions being evaluated for truth on a variable assignment or at a possible world in order to accommodate constructions such as 'The thing believed by Tim is necessary' or 'Tim believes that $p$ for some $p^{\prime}$. I could, equally, have spoken of correlation as a more complex relation, relating a Russellian content alongside its 'vehicle matrix' to some other Russellian content and vehicle matrix. The schematic truth-conditions would then run: 'NN believes that $S$ ' is true on an occasion of use if and only if the R-proposition expressed by 'that $S$ ' (at $c$ ) correlates with an R-proposition expressed by the belief ${ }^{+}$state of $\mathrm{NN}$, and the vebicle matrix determined by 'that $S$ ' correlates with a vehicle matrix determined by the belief ${ }^{+}$state of $\mathrm{NN}$, where the standards for correlation are those operative at $c$. The diagram of $\mathrm{Ba}$ and Ia's exchange above would then look as follows:

$$
\begin{aligned}
& \mathrm{Ba}: \quad<0, \text { brightness }>,<\mathrm{R}^{1}{ }_{\mathrm{Ba}}, \mathrm{R}_{\mathrm{Ba}}^{2}> \\
& \text { Ia: } \quad<0, \text { brightness }>,<\text { 'Hesperus', 'is bright' }>
\end{aligned}
$$

This diagrammatic change should serve to illustrate the terminological nature of the choice.

Let us first explore how the framework handles notorious 'Ortcutt' (or 'double vision') cases (introduced to the literature by Quine (1956)). Suppose Ann is up late reading in bed when she hears suspicious rustling from outside. Fearing that her prize-winning vegetables are being sabotaged by a jealous neighbour, she steps out onto the porch, at time $t$, and fixes her gaze on

${ }^{21}$ These truth-conditions will be augmented in $§ 4$. 
the bushes from which all the noise seems to be coming. After some hesitation, she plucks up the courage to investigate. She supposes that her cat, Bruce, is likely trailing not far behind her. But once Ann reaches the bushes she realises, at $t^{\prime}$, that Bruce-whom she had mistakenly locked outside—was responsible for the noise all along. Her two grandchildren, knowingly watching the events unfold from their window, might have had the following conversation at $t$, as Ann stepped outside:

(5) A: Ann believes that Bruce is a fox hiding in the bushes!

(6) B: No, Ann believes that Bruce is her neighbour, Casey, sabotaging her vegetables.

Two neighbours unaware of the noise or the creature responsible for it, but seeing that Ann is out in the garden, might have simultaneously had a different conversation, in which they hypothesise only about whether Ann is aware of Bruce's curious nature:

(7) C: Ann believes that Bruce is curled up asleep on the sofa.

(8) D: No, Ann believes that Bruce is curiously trailing behind her.

I take it that, in our scenario, the de re belief reports in (5) and (7) are false, while those in (6) and (8) are true. The important thing to note is that each conversation has its own standards for resolving which object-representation in Ann's mind is correlated with the use of 'Bruce'. These ways of resolving the unspecificity in which object-representation of the subject's is to be correlated with the name 'Bruce' are incompatible with one another. No single context would easily accommodate both conversational threads, since different requirements on correlation are in play. This explains the invalidity of the inference from (9) and (10) to (11):

(9) Ann thinks that Bruce is Casey.

(10) Ann thinks that Bruce is curiously scampering around behind her. 
(11) Therefore, Ann thinks that Casey is curiously trailing behind her.

Quite generally, if the subject has multiple representational vehicles concerning a single thing (in the sense that it is in principle possible for them to rationally take conflicting attitudes ${ }^{+}$to contents which are singular with respect to that thing), there will be cases in which it is important for the context to resolve a de re ascription, for there will be multiple eligible candidates which may be correlated with the singular term in the reports 'that-' clause, and which one is correlated may affect the truth-value of the report.

In the first instance, correlation relates sticky propositions. It will be congenial in what follows, however, to also talk of correlation relations between the constituents of sticky propositions, in a derivative sense. ${ }^{22}$ Ascriptions (5)-(8) briefly explored the mechanics of correlation between singular terms. But correlation extends to all sorts of expressions appearing in the 'that-' clauses of attitude reports. Suppose Lisa is trying to figure out where it would be best to hang a picture in her new office. Looking at the frame, she judges ${ }^{+}$it, explicitly, to be roughly 30 centimetres in length along each edge. At most contexts, the following report will intuitively be true:

Lisa thinks the frame is roughly 12 inches long.

In this case, the use of the predicate 'is roughly 12 inches long' is correlated with a vehicle exercised by Lisa which would, in certain stricter contexts (where the standards for correlation are more stringent), be truly reported only by instead using the predicate is roughly 30 centimetres long'. I will call contextual variation in what is required in order for two expressions to correlate the transparency/opacity scale.

22 Further motivation for taking sub-propositional correlation as derivative is suggested by cases in which it matters where in the sticky proposition a vehicle appears. (See the discussion of (12)-(13) below.) 
The foregoing discussion should indicate the framework's general plausibility. This is important. If the semantics required by acquaintance theorists is independently motivated, the liberal's trademark argument should lose the force it has long been taken to have.

Consider, then, the solution it offers to a further puzzle case, much-discussed in recent literature. Rosaline, Maria, and Katherine are to attend a masked ball.

Each lady anticipates (tepidly) the attentions of a different suitor, and each suitor has given his lady a favour to wear, by which he hopes to recognize her during the masque. The ladies, with malice aforethought, decide to swap favours and so cause the suitors to 'woo contrary' (Cumming, 2007, p. 83).

The exchange of favours is represented in the figure below.

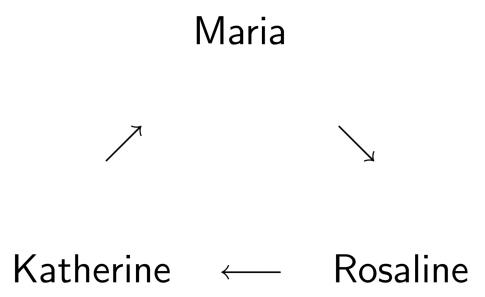

- Figure $1 .^{23}$

At the evening's first dance, Biron, originally intended for Rosaline, takes Katherine's hand. Maria remarks:

(12) Biron thinks Katherine is Rosaline.

Her remark is true, yet in the same circumstances the following seems false:

23 (Cumming, 2007, p. 84). 
(13) Biron thinks Rosaline is Katherine.

The puzzle is that Biron appears to be irrational, at least assuming the 'is' here expresses identity (a symmetric relation), since he fails to believe a trivial logical consequence of what he believes. Cumming (2007) uses this puzzle to suggest that names are not singular terms. Can our semantic framework provide a less dramatic treatment of the puzzle?

The parallels between (12)-(13) and (9)-(11) should be encouraging. On the reading required to generate the irrational entailment (that Biron believes $a=b$ but not $b=a$ ), each occurrence of 'Rosaline' in (12)-(13) and of 'Katherine' in (12)-(13) must occur with the same degree of transparency/opacity. However, these are not the readings responsible for the intuitive, divergent truth-value assignments. On the natural diagnosis, 'Katherine' appears transparently in (12) and 'Rosaline' opaquely. What this means is that, in (12), the constraints required for 'Katherine' (roughly, given its grammatical position) to correlate with a representational vehicle in Biron's mind do not extend beyond preservation of reference. In contrast, the constraints required for 'Rosaline' (roughly, given its grammatical position) to correlate with a representational vehicle in Biron's mind are more substantive. To use the metaphor of mental files, what the truth of (12) requires is, roughly, that information gathered by Biron's perceptual object-representation of the thing which is in fact Katherine is feeding into his standing file on Rosaline. ${ }^{24}$ This condition is satisfied in our scenario, and so (12) comes out true.

Constructions in the form of (12) and (13) have a general tendency to promote transparent readings of the grammatical subject and opaque readings of the grammatical object. ${ }^{25}$

\footnotetext{
24 While it is useful to adopt the 'file' metaphor here, I need not incur the commitments associated with prominent file-theorists (e.g. Récanati, 2012). The notion of a representational vehicle I assume is lightweight, corresponding just to whatever cognitive resources a thinker reliably employs in her representations as of a particular object (or plurality). There is no assumption that these 'files' correspond to those talked about in, say, discourse representation theory. (Note that Cumming (2007, p. 85), in his solution, appeals to 'deictic mental symbols used to track objects'.)

25 Not always, however. Suppose Rosaline scalds Biron. He might excuse himself with either 'I thought you were her!' or 'I thought she was you!' Likewise, there appear to be ways of making a use of (13) felicitous.
} 
Indeed, the same sort of explanation can be given of (13)'s falsity. In (13), 'Rosaline' appears transparently and 'Katherine' opaquely. What this means is that the constraints required for 'Rosaline' (roughly, given its grammatical position) to correlate with a representational vehicle in Biron's mind do not extend beyond preservation of reference. In contrast, the constraints required for 'Katherine' (roughly, given its grammatical position) to correlate with a representational vehicle in Biron's mind are more substantive. In file-talk, what the truth of (13) requires is, roughly, that information gathered by Biron's perceptual object-representation of the thing which is in fact Rosaline is feeding into his standing file on Katherine. This condition is not satisfied in our scenario, and so (13) comes out false. The truth in the vicinity, of course, is that Biron thinks Rosaline is Maria.

In sum, our framework explains the divergent truth-values of (12) and (13) as follows. The 'that-' clause of Maria's utterance of (12) expresses the following sticky proposition:

$$
<<=\text {, 'is' }>,<k, \text { 'Katherine' }>,<r \text {, 'Rosaline' }>>
$$

At the context at which (12) is uttered, the sticky proposition its 'that-' clause expresses is correlated with at least one sticky proposition expressed by Biron's belief ${ }^{+}$state, namely:

$$
<<=\text {, 'is' }>,<k, \mathrm{R}_{\text {Biron }}>,<r, \mathrm{R}_{\text {Biron }}^{2}>>
$$

In contrast, the sticky proposition determined by the 'that-' clause of an utterance of (13) at the same context, illustrated below, is not correlated with the above sticky proposition, nor with any other in the space of Biron's belief ${ }^{+}$state.

$$
<<=\text {, 'is' }>,<r \text {, 'Rosaline' }>\text {, }<k \text {, 'Katherine' }>>
$$

Cumming (2007, p. 86, n. 16) brings this out using the following dialogue: 'Who does Biron think Rosaline is?'; 'He thinks Rosaline is Katherine'. 
This fails to be correlated with the same sticky proposition with which the 'that-' clause of (12) is correlated partly due to the quasi-grammatical structure preserved by sticky propositions, in virtue of which the sticky proposition determined by (12) is distinct from that determined by (13). Again, constructions in the form of (12) and (13) have a quite general tendency to promote transparent readings of the grammatical subject and opaque readings of the grammatical object.

Before moving on to elucidate how the contextualist proposal above can be used in answer to the argument from attitude reports in $\$ 1$, now is a good time to assuage a couple of potential concerns.

In what sense is the opacity/transparency distinction a 'sliding scale' or a matter of degree? Reporting beliefs is not like direct quotation. Attitude reports cannot embed the very vehicles of thought which subjects themselves use. And accuracy or faithfulness to the way in which a subject thinks of a thing will come in degrees. For example, in the example of Lisa above, where Lisa uses a cognitive vehicle she might most faithfully give voice to by saying 'roughly 30 centimetres', an attributor might, depending on the standards at the context of use, felicitously use 'roughly 30 centimetres', 'roughly 12 inches', or even 'roughly the length of a sheet of A4'. Familiarly, in the same sort of way, 'Clark Kent' can be more accurate to a subject's way of thinking of a person than 'Superman'-with the felicity of an alternative device such as 'That person' (pointing to the man himself) perhaps falling somewhere in between.

Isn't it often true to ascribe beliefs to subjects concerning things about which they have no representational vehicle? I venture that you, the reader, believe that Palermo is north of Malawi and that $7935+$ $8226=16161$, despite you having never explicitly reflected on the matter. Often these are called 'tacit' or 'dispositional' beliefs, the idea being that while the subject does not believe ${ }^{+}$the proposition attributed, they could be brought to do so with gentle coaxing given what they do believe $^{+}$. There is simply no requirement in the proposal articulated here that there must be a representational vehicle in the mind of the subject for each expression in the 'that-' clause of a true attitude report. There may often be cases in which a vehicle in fact utilised by the subject bears an underwhelming relationship to one used in the 'that-' clause of a true attitude report, contextual standards being sufficiently weak as to permit correlation nonetheless. If, say, a 
subject lacks the aesthetic concept yugen, it can still be appropriate to ascribe to them beliefs in the instantiation of this property if their response to a certain piece of art is suitably suggestive, just like, more dramatically, it can be appropriate to ascribe to a chess-playing computer the belief that it should get its queen out early on the basis of its playing patterns. ${ }^{26}$ In each of these cases, the representational system may have some low-level or approximate representation of the thing(s) in question, which is apt, at felicitous contexts, to be a constituent in a correlated sticky proposition. But if there are cases where it does not, we can allow that the sticky proposition determined by a 'that-' clause may correlate with a 'gappy' sticky proposition-a sequence containing the R-proposition some of whose constituents fail to be associated with vehicles of the subject's belief ${ }^{+}$state. $^{27}$

What I have been concerned to provide in this section is a promising elaboration of the kind of contextualist framework required by the acquaintance-theorist in her response to the argument from attitude reports in $\$ 1$. This remains a blueprint, requiring more sophisticated refinement in its details. We turn now to its deployment.

\section{Correlation without co-valuation}

We are now in a position to use our contextualist semantics to motivate a fresh look at the reporting data represented by (3), which form the heart of the argument against CONSTRAINT.

De re attitude ascriptions require for their truth that the singular sticky proposition determined by 'that $S$ ' be correlated, by contextually determined standards, with a sticky proposition determined by the attributee's attitude ${ }^{+}$state. Most of those who have discussed the general sort of semantics I am offering for attitude ascriptions have taken sameness of R-

\footnotetext{
26 The latter example is Dennett's (1978).

${ }^{27}$ Richard (2013, pp. 13-25) provides a detailed discussion of accommodating dispositional attitudes in the present sort of framework.
} 
proposition to be a necessary condition for the truth of an ascription. ${ }^{28}$ In that case, the sticky proposition determined by the subject's attitude ${ }^{+}$state must also be singular. However, we should reject the principle that correlation requires 'co-valuation' (sameness of semantic value). Some attitude ascriptions do not demand for their truth that the R-proposition be preserved across correlation. This will be the key to providing truth-conditions for ascriptions such as (3).

(3) The Queen believes that Bond is a hero.

In the scenario of (3), a (fairly idealised) toy model of the sticky proposition determined by the Queen's belief $^{+}$state would be:

$$
<<\iota x F x, \mathrm{R}^{1}{ }_{\mathrm{Q}}>,<\text { is a bero, } \mathrm{R}^{2}{ }_{\mathrm{Q}}>>
$$

$\mathrm{R}^{1} \mathrm{Q}$ is a representational vehicle whose translation into English might be 'the top-performing spy chosen by the assistants'. ${ }^{29}$ This expresses a quantificational constituent of a Russellian proposition, $\iota \times F \times . \mathrm{R}_{\mathrm{Q}}^{2}$ expresses the property is a hero. In contrast, the sticky proposition determined by the 'that-' clause of M's report in (3) is:

$$
<<b \text {, 'Bond' }>,<\text { is a hero, 'is a hero' }>>
$$

Here, $b$ is the res of the ascription-Bond himself. In this case, the R-proposition is not preserved across correlation. The R-proposition of M's use of 'Bond is a hero' in (3) is $<b$, is a hero $>$, whereas the R-proposition corresponding to the relevant sticky proposition determined by the Queen's belief ${ }^{+}$state is $\langle\iota x F x$, is a hero $>$. In spite of this, our contextualist semantics

${ }^{28}$ Fodor (1990) and Richard (1990; 2013) inter alia explicitly endorse this constraint; only Chalmers (2011), Goodman (2013; 2017), and Récanati (1993) reject it.

${ }^{29}$ I idealize here in many ways, of course. It is also unlikely that the description is purely qualitative-lacking any singular material for, e.g., time and location. But the description need not contain a term referring to Bond. 
provides the resources for an explanation as to how the two sticky propositions satisfy the requirements for correlation. At the envisaged context, it suffices for correlation between $<b$, 'Bond' $>$ and $<\iota x F x, \mathrm{R}_{\mathrm{Q}}^{1}>$ that $b$ alone is in the extension of ' $F$ ' ('the top-performing spy chosen by the assistants'), as expressed by the belief ${ }^{+}$state of the Queen. At contexts like that in (3), contextually relevant factors such as the purposes, expectations, and presuppositions in play mean that attributors may refer to the object which in fact satisfies the definite description constituent of the subject's belief ${ }^{+}$state. Perhaps what is important in the context of (3), for example, is that the audience of the clandestine ceremony are in a position to entertain singular thoughts about Bond (in virtue of their being acquainted with him).

In a slogan, then: correlation does not require co-valuation. Indeed, at some contexts, mental correlates of indefinite descriptions appear to suffice for the truth of a de re attitude report. Recall the case of (4). There, the standards in play at the context are sufficiently diluted as to allow Alice's descriptive content-vehicle (akin to 'all philosophers') to be correlated with Phyllis' use of 'I'.

The principal goal in this paper has been to offer an attractive way of defending the conjunction of acquaintance-theoretic conceptions of singular thought with natural semantic principles linking singular thought to our ordinary talk about the attitudes. The contextualist semantics articulated here allows this. Moreover, it does so in a way which preserves the traditional acquaintance-theoretic explanation of the falsity of reports like (2), above. These sorts of cases are those which take place at contexts at which the standards required for correlation are not so diluted that correlation between attributor's singular (sticky) proposition and attributee's descriptive (sticky) proposition suffices for the report's truth. And, in order to entertain a singular content about some spy, Ralph must be acquainted with that spy. The mere fact that cases like (3) are possible does not infringe on this sort of explanation. Despite the claims of prominent liberals that 'CONSTRAINT has no explanatory value whatsoever when it comes to the acceptability of [de re] attitude reports' (Hawthorne and Manley, 2012, p. 39), then, acquaintance can have a systematic role to play in the truth-conditions of attitude reports, after all. 
Of course, it would be nice if there were precedents supporting the denial of the 'covaluation' principle. In fact, the case of Lisa, above, figuring out where to hang her picture, provides just such a precedent. Looking at the frame, we said, Lisa might explicitly judge ${ }^{+}$it to be roughly 30 centimetres in length. But at most contexts the following report

Lisa thinks the frame is roughly 12 inches long.

will nonetheless be true. In this case, the use of the predicate 'is roughly 12 inches long' is correlated with a vehicle exercised by Lisa which would, in certain stricter contexts, be truly reported only by using the predicate 'is roughly 30 centimetres long'. But being roughly 30 centimetres long and being roughly 12 inches long are distinct properties. As a result, the Rproposition expressed by the 'that-' clause of the attitude report is distinct from the Rproposition expressed by Lisa's belief ${ }^{+}$state.

Consider another example:

(14) Charley wants a hat just like mine.

On its most natural reading, (14) falls under Fodor's category of the 'non-specific de re' (1970, pp. 239-43). To access this reading, suppose that what Charley wants is any hat which is a Dodgers baseball cap. (14) will be true, on this reading, if it is also the case that, perhaps unbeknownst to Charley, the speaker owns a Dodgers baseball cap. A wealth of semantic treatments have been proposed for these readings of such reporting constructions (see von Fintel and Heim (2011, pp. 99-117)). Making the case for one of these would require a long digression. The only observation I wish to make is that these readings appear to run against the co-valuation principle. The report's 'that-' clause expresses a proposition which has, as a constituent, the property of being a hat like the speaker's. But Fodor's (1970) point is that the proposition Charley entertains has a different property as a constituent: namely, the property of being a Dodgers hat. 
In the remainder of the paper, I briefly discuss an important and unacknowledged obstacle to positing violations of the co-valuation principle. Removing this obstacle is crucial to safeguarding the acquaintance theorist's response to the argument from attitude reports.

\section{Barriers to rejecting co-valuation}

Consider the following sort of case used by Chalmers (2011, pp. 615-6) to motivate a rejection of his analogue of the co-valuation principle. Yusuf and Zoe are basketball coaches for children. Yusuf notes:

(15) Jack is tall.

His use of 'tall' at the context picks out the property tall. Later, Zoe is alone coaching young adults. At the later context, a similar use of 'tall' would pick out a different property: tall. At this context, Chalmers (2011, p. 615) observes, 'Jack is tall' would be false. Jack may be tall for a child, but he is short compared to the young adults. Nevertheless, Zoe's report

(16) Yusuf believes that Jack is tall.

remains intuitively true, despite the fact that a use of 'tall' at her context picks out tall 2 as opposed to tall. In the terms of the semantic framework adopted here, the truth of Zoe's ascription seems to require correlation between the two sticky propositions below.

$$
\begin{aligned}
& <<j \text {, 'Jack' }>,<\text { tall, 'is Tall' }>> \\
& <<j, \mathrm{R}_{\mathrm{Y}}^{1}>,<\text { tall }_{2}, \mathrm{R}_{\mathrm{Y}}^{2}>>
\end{aligned}
$$


Chalmers (2011) concludes that if we are to account for the truth of Zoe's utterance of (16), we must reject the co-valuation principle, for tall and tall 2 are distinct properties.

Unfortunately, we cannot motivate denials of the co-valuation principle in this way. There may be cases in which the two relevant R-propositions differ in truth-value. And where the attitude verb of the report is factive, it might be that instances of the following (arguably nonnegotiable) inference pattern fail to hold: where $\Psi$ is a factive attitude verb,

$$
\begin{aligned}
& S \Psi \text { s that } p \text {. } \\
& \text { Therefore, } p \text {. }
\end{aligned}
$$

It is a corollary of Chalmers' (2011) claims about the above case that the following report may be true (as used at a context $c$ ) despite the falsity of 'Jack is tall' (as used at $c$ ).

(17) Yusuf knows that Jack is tall.

This happens if, as in the scenario described, the R-proposition entertained by Yusuf, $\left\langle j\right.$, tall $\left._{1}\right\rangle$, is true while the R-proposition expressed by the 'that-' clause of the attitude report, $\left\langle j\right.$, tall $\left._{2}\right\rangle$, is false, since the individual (Jack) fails to instantiate the property tall 2 . In that case, a variety of inference patterns which seem constitutive of factive attitude verbs are invalid:

\section{Someone knows that $p$. \\ Therefore, $p$.}

In fact, the problem extends beyond arguments involving factive attitude verbs to arguments otherwise about the truth-values of beliefs. For example, the following pattern of argument is intuitively valid:

Yusuf believes that $p$. 
It is not the case that $p$.

Therefore, Yusuf believes falsely that $p$.

I take it that the acquaintance theorist should refrain from motivating her rejection of the covaluation principle in the way suggested by Chalmers (2011). But the more general threat is that any account which posits violations of the co-valuation principle may invalidate the inference patterns above. And this is a consequence worth avoiding. Before closing, then, I explain our intuitive assessment of the truth of (16) and (17) in a way which preserves not only the plausible inference patterns above but also the violations of co-valuation needed by the acquaintancetheorist.

While there are felicitous readings of (16) and (17), it is worth remembering that the context is ex hypothesi one at which a use of (15) comes out false. This makes the fact that the reporter nonetheless decides to say Yusuf knows or believes that it is true a little mysterious. It is natural to instead suggest that (16) and (17) are true at the later context only to the extent that a use of (15) might itself come out true at that same context. Context-sensitive expressions can be used deferentially. In Zoe's use of the expression 'tall' (in (16) and (17)), there is a covert argumentplace for the old context at which 'tall' expresses a property Jack does instantiate. To the extent that the report is true, it is not the case that it is true while its 'that-' clause expresses the same proposition as the false use of (the homophonous but perhaps distinct construction) 'Jack is tall' to which Chalmers (2011) draws our attention. In that case the above inference patterns can be safely preserved along with the truth of (16) and (17) in the envisaged scenario.

That context-sensitive expressions like 'tall' can be used deferentially should not be surprising. It is well-known that terms like 'local' can be used in precisely this way. The entailments of Chalmers' (2011) claims about 'tall' concerning 'local' look beyond the pale. By subscripting the deferential uses of context-sensitive terms like 'local', we can reveal the various equivocations. For example,

Dave believes there is a local $\operatorname{bar}_{D}$ (i.e. local to Dave) that sells beer. 
It is not the case that there is a local bar (i.e. local to the speaker) that sells beer.

Therefore, Dave falsely believes there is a local $\operatorname{bar}_{D}$ (i.e. local to Dave) that sells beer.

Crucially, none of these issues impair our proposed treatment of reports such as (3), which entails violations of co-valuation. The R-proposition expressed by the 'that-' clause of the report, $<b$, is a hero $>$, entails the truth of the R-proposition expressed by the belief ${ }^{+}$state of the Queen, $<\iota x F x$, is a hero $>$. The R-proposition entertained by the Queen, being quantificational, is at a level of generality above the singular R-proposition expressed by the attributor's 'that-' clause. Given that in these kinds of cases, to which the liberal's argument appeals, the attributors refer to some thing which in fact satisfies the description entertained by the subject, it will not be the case that a corresponding knowledge report is true at some context $c$ despite the falsity of the Rproposition expressed by the report's 'that-' clause at $c$. And so, given that Bond is the unique individual picked out by $\iota \times F \times$ as tokened by the Queen's belief ${ }^{+}$state, it will not be the case that (18), below, is true at a context $c$ despite the falsity of the R-proposition expressed by 'Bond is a hero' at $c$.

The Queen knows that Bond is a hero.

This pattern will hold throughout the cases to which liberals appeal in the argument against CONSTRAINT. ${ }^{30}$

\footnotetext{
${ }^{30} \mathrm{I}$ have encountered the objection that once we reject the co-valuation principle, no effective constraints are placed on correlation. What, then, is to prevent the framework from allowing 'Paul believes his pen is blue' to be a true report of Paul's belief ${ }^{+}$that his table is brown? In response, it is not that no constraints are placed on correlation. Rather, what the operative constraints on correlation are is a context-dependent matter. To ask whether 'Paul believes his pen is blue' could truly report Paul's belief ${ }^{+}$that his table is brown is therefore to ask whether there is a possible context at which the sticky proposition expressed by 'Paul believes his pen is blue' (on that occasion of use) correlates with that expressed by Paul's belief ${ }^{+}$state. For there to be a problem here, we would need a positive reason for thinking that such a context is possible. But it is far from clear that there is any. Moreover, if there were such a context, we would again be presented with violations of the factivity inference pattern. It may be insisted that the universal validity of the factivity inference pattern gives
} 


\section{Conclusion}

Given the flexibility of the contextualist semantics articulated here, it is possible to reconcile HARMONY and the intuitive truth-value assignments for de re attitude reports like (3) and (4) with very demanding views on what it takes to be acquainted with an object. It was dialectically important here to show that the acquaintance theorist has the resources to accommodate any case conceived of by the arguer in which a de re attitude report about $S$ is intuitively true without $S$ being acquainted with the res. A result of this is that the acquaintance theorist has the resources to view virtually all of our ordinary attitude reporting practices as taking place at contexts where the standards for correlation fall far short of those imposed by her theoretical, joint-carving terms of art-'entertains', 'singular thought', etc. It might be that scenarios like (3), or even (4), most closely model the ascription practices of the folk, if most of the thoughts we entertain about objects in the world are taken to be mediated by descriptions (à la Russell (1910/11)). More generally, we might worry that detaching (to a context-dependent degree) a theoretical account of singular thought from the data of ordinary language, de re attitude reports leaves us with scant data to govern such an account in the first place. Accordingly, the broader upshot of the strategy defended here is double-edged. While the framework liberates us to consider even the most demanding conceptions of 'acquaintance', as it appears in CONSTRAINT, it highlights the urgency of an appraisal of the theoretical-explanatory role of singular thought.

us some guidance on what possible contexts there might be, and what possible correlation relations there might be. 


\section{References}

Bach, K. (1994). Conventional impliciture, Mind \& Language, 9(2), 124-162.

Bach, K. (1997). Do belief reports report beliefs?. Pacific Philosophical Quarterly, 78(3), 215-241.

Bach, K. (2010). Getting a thing into a thought. In R. Jeshion (ed.), New Essays on Singular Thought. Oxford: Oxford University Press.

Bach, K. (2014). Consulting The Reference Book. Mind \& Language, 29(4), 455-474.

Borg, E. (2004). Minimal Semantics. Oxford: Oxford University Press.

Braun, D. (1988). Understanding belief reports. Philosophical Review, 107, 555-595.

Burge, T. (2007). Postscript to 'Belief de re'. In his Foundations of Mind. Oxford: Oxford University Press.

Chalmers, D. J. (2011). Propositions and attitude ascriptions: a Fregean account. Noûs, 45(4), 595639.

Crane, T. (2013). The Objects of Thought. Oxford: Oxford University Press.

Crimmins, M. (1992). Talk. About Beliefs. Cambridge, MA: MIT Press.

Crimmins, M. (1995). Notional specificity. Mind \& Language, 10(4), 464-477.

Crimmins, M., and Perry, J. (1989). The prince and the phone booth: reporting puzzling beliefs. Journal of Philosophy, 86(12), 685-711.

Cumming, S. (2007). Proper Nouns. PhD thesis submitted to Rutgers: The State University of New Jersey.

Cumming, S. (2013). From coordination to content. Philosopher's Imprint, 13(4), 1-16.

Davies, M. (1981). Meaning, Quantification, Necessity: Themes in Philosophical Logic. London: Routledge.

Dennett, D. (1978). Brainstorms. Cambridge, MA: MIT Press.

Dorr, C. (2011). De re a priori knowledge. Mind, 120(480), 939-991.

Evans, G. (1982). The Varieties of Reference. Oxford: Oxford University Press. 
von Fintel, K., and Heim, I. (2011). Intensional Semantics. Manuscript, MIT. http://web.mit.edu/fintel/fintel-heim-intensional.pdf. Accessed June 2016.

Fodor, J. A. (1990). Substitution arguments and the individuation of belief. In J. A. Fodor (ed.), $A$ Theory of Content and Other Essays. Cambridge, MA: MIT Press.

Fodor, J. D. (1970). The Linguistic Description of Opaque Contexts. $\mathrm{PhD}$ thesis submitted to the Massachusetts Institute of Technology.

Forbes, G. (1987). A dichotomy sustained. Philosophical Studies, 51, 187-211.

Goodman, R. (2013). Singular Thought: Making the Most of the Notion. PhD thesis submitted to the University of Chicago.

Goodman, R. (2017). Do acquaintance theorists have an attitude problem? Australasian Journal of Philosophy.

Harman, G. (1977). How to use propositions. American Philosophical Quarterly, 14(2), 173-6.

Hawthorne, J., and Manley, D. (2012). The Reference Book. Oxford: Oxford University Press.

Hawthorne, J., and Manley, D. (2014). Response. Mind \& Language, 29(4), 499-510.

Jeshion, R. (2010). Singular thought: acquaintance, semantic instrumentalism, and cognitivism. In R. Jeshion (ed.), New Essays on Singular Thought. Oxford: Oxford University Press.

Jeshion, R. (2014). Two dogmas of Russellianism. In M. García-Carpintero and G. Martí (eds.), Empty Representations: Reference and Non-Existence. Oxford: Oxford University Press.

Kaplan, D. (1968). Quantifying in. Synthese, 19(1), 178-214.

Kaplan, D. (1989). Demonstratives. In J. Almog, J. Perry, and H. Wettstein (eds.), Themes from Kaplan. Oxford: Oxford University Press.

Lewis, D. K. (1979). Attitudes de dicto and de se. Philosophical Review, 88(4), 513-543.

Lewis, D. K. (1996). Elusive knowledge. Australasian Journal of Philosophy, 74(4), 549-567.

Loar, B. (1988). Social content and psychological content. In R. Grimm and D. Merrill (eds.), Contents of Thought. Tucson: University of Arizona Press.

McDowell, J. (2009). The Engaged Intellect. Cambridge, MA: Harvard University Press. 
Millikan, R. (2000). On Clear and Confused Ideas: An Essay about Substance Concepts. Cambridge: Cambridge University Press.

Peacocke, C. (1983). Sense and Content. Reprinted, Oxford: Oxford University Press, 1999.

Quine, W. V. O. (1956). Quantifiers and propositional attitudes. Journal of Philosophy, 53(5), 177-187.

Quine, W. V. O. (1977). Intensions revisited. Midwest Studies in Pbilosophy, 2(1), 5-11.

Récanati, F. (1993). Direct Reference: from Language to Thought. Oxford: Blackwell.

Récanati, F. (2010). Singular thought: in defence of acquaintance. In R. Jeshion (ed.), New Essays on Singular Thought. Oxford: Oxford University Press.

Récanati, F. (2012). Mental Files. Oxford: Oxford University Press.

Richard, M. (1990). Propositional Attitudes: An Essay on Thoughts and How We Ascribe Them. Cambridge: Cambridge University Press.

Richard, M. (2013). Context and the Attitudes: Meaning in Context, vol. 1. Oxford: Oxford University Press.

Russell, B. (1910/11). Knowledge by acquaintance and knowledge by description. Proceedings of the Aristotelian Society, 11(5): 108-128.

Salmon, N. (1986). Frege's Puгzle. Cambridge, MA: MIT Press.

Schiffer, S. (1978). The basis of reference. Erkenntnis, 13, 171-206.

Soames, S. (1987). Direct reference, propositional attitudes, and semantic content. Philosophical Topics, 15(1), 47-87.

Sosa, E. (1970). Propositional attitudes de dicto and de re. Journal of Philosophy, 67(21), 883-896.

Stalnaker, R. C. (1984). Inquiry. Cambridge, MA: MIT Press.

Stalnaker, R. C. (1988). Belief attribution and context. In R. H. Grimm and D. D. Merrill (eds.), Contents of Thought. Tucson, AZ: University of Arizona Press.

Strawson, P. F. (1959). Individuals. London: Methuen. 